\title{
Chậm đổi mới, doanh nghiệp sẽ thất bại
}

\author{
TUOI TRE ONLINE
}

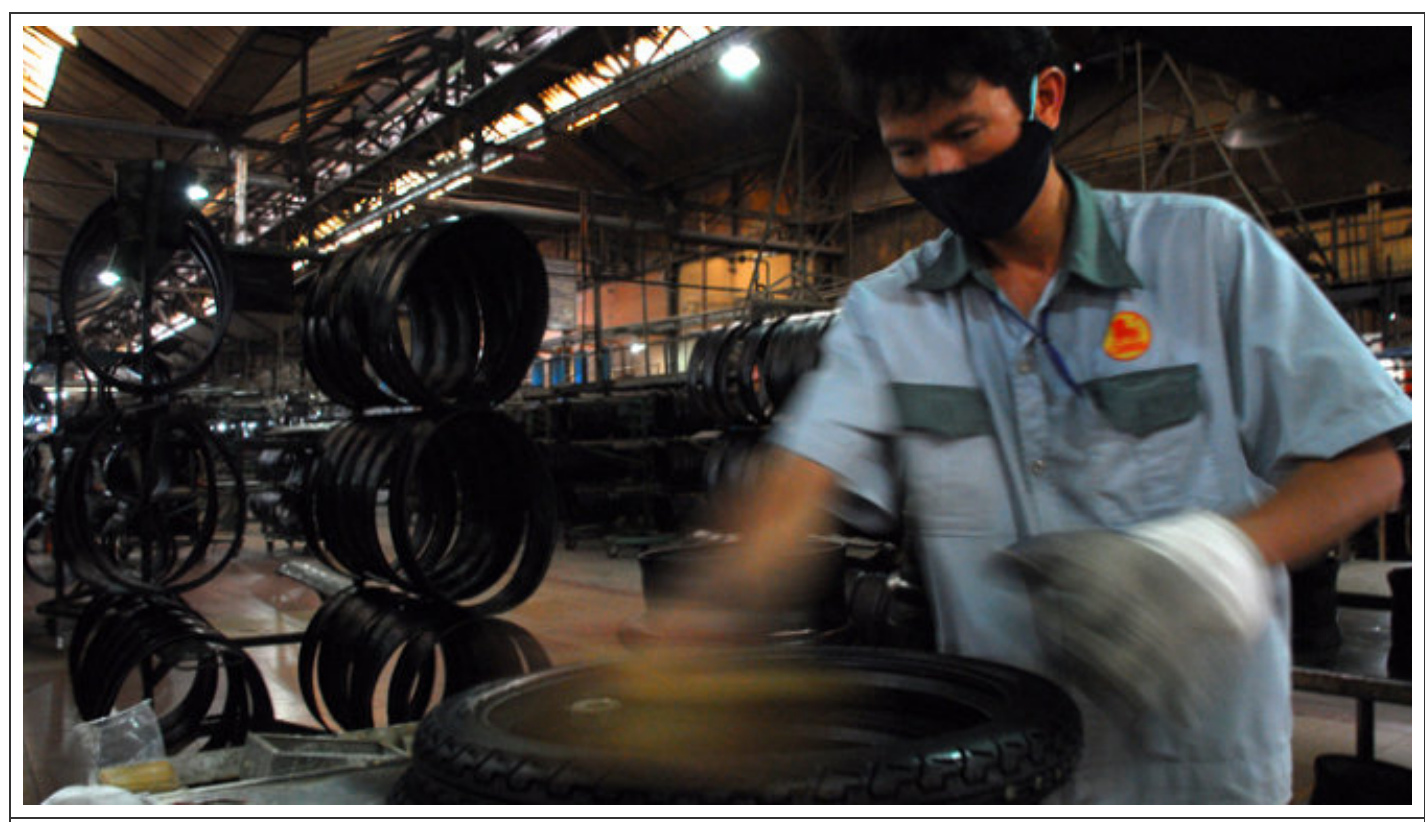

Sản xuất cao su tại Công ty cổ phần Công nghiệp cao su miền Nam, Q.Thủ Đức, TP.HCM - Ảnh: H.T.Vân

Trao đổi với chúng tôi nhân sự kiện này, bà Vũ Kim Hạnh - giám đốc BSA, một trong hai đơn vị tổ chức xây dựng bộ tiêu chí này - cho biết: Đổi mới công nghệ và quản trị là câu chuyện sống còn của DN ở thời điểm hiện nay. Tuy nhiên, mục đích của chúng tôi không phải để bình chọn ra những $\mathrm{DN}$ đổi mới sáng tạo để trao danh hiệu, mà điều quan trọng là cùng với $\mathrm{DN}$ đánh giá lại quá trình đổi mới sáng tạo vừa qua, nhận ra điểm mạnh yếu, yêu cầu hệ thống hóa và nâng cao hiệu quả của bản thân các hoạt động đổi mới sáng tạo.

Bộ tiêu chí đo lường năng lực đổi mới sáng tạo của doanh nghiệp (i2Metrix) được BSA và Công ty nghiên cứu DHVT đưa ra gồm năm tiêu chí tương thích với bộ tiêu chí của Liên Hiệp Quốc cũng như các quốc gia phát triển, hướng đến xu thế hội nhập của doanh nghiệp Việt.

Theo bà Vũ Kim Hạnh, i2Metrix có thể được xem như một máy đo nhịp tim hay một la bàn giúp doanh nghiệp định hướng rõ hơn trong công cuộc đổi mới, sáng tạo để phát triển bền vững. Thông qua bộ tiêu chí này, các doanh nghiệp sẽ tự đo lường năng lực đổi mới sáng tạo của mình.

* Sau quá trình khảo sát, bà có thể cho biết có sự khác nhau như thế nào giữa những DN có đầu tư cho đổi mới sáng tạo và những $\mathrm{DN}$ còn lại?

- Gần một năm đồng hành với DN hỗ trợ họ về đổi mới công nghệ và quản trị, chúng tôi hiểu đây chính là câu chuyện sống còn của $\mathrm{DN}$ ở thời điểm hiện nay. Càng hội nhập sâu hơn với nền kinh tế thế giới, càng cạnh tranh khốc liệt hơn với hàng hóa dịch vụ các nước, ta càng thấy tầm quan trọng của năng suất, chất lượng, giá thành, tức là những yếu tố đầu vào của sản phẩm.

Với nhiều DN VN hiện nay, quá trình từ đưa ra ý tưởng, nghiên cứu thị trường tới thiết kế sản phẩm, chọn phương án sản xuất cho đến tập hợp nguồn lực để đưa vào sản xuất... chưa được thực hiện căn cơ. Sản phẩm chưa ra thị trường đã yếu về năng lực cạnh tranh do công nghệ và thiết bị lạc hậu, năng suất lao động và năng lực sản xuất kém cạnh tranh.

Khi trò chuyện với $19 \mathrm{DN}$ dẫn đầu (lựa chọn từ hơn $500 \mathrm{DN}$ hàng VN chất lượng cao), 
chúng tôi phát hiện những DN này ngay từ khi mới thành lập DN đã đổi mới sáng tạo. Kết quả là họ đang phát triển khá ổn định, vững chắc.

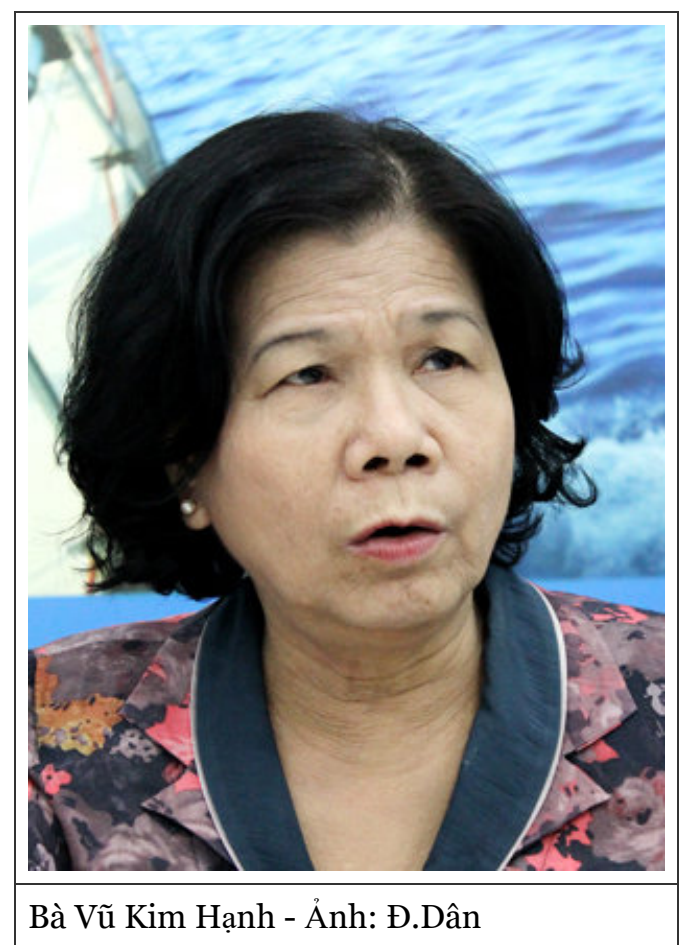

* Bà có thể nêu cụ thể một số thành quả mà các DN đã đạt được khi đầu tư cho đổi mới sáng tạo?

- Những thành quả này là các con số rát... định lượng chứ không chung chung như những báo cáo thành tích, dù họ ít khi nói về những con số này. Ví dụ, Dược Hậu Giang ứng dụng 90 sáng kiến làm lợi được 29 tỉ đồng; Minh Long I giảm tiêu hao năng lượng được $70 \%$, giảm phế phẩm từ vài chục phần trăm còn $5-10 \%$, nâng công suất máy từ 20.000 sản phẩm/ ngày đến 100.000 sản phẩm/ ngày. Và còn nhiều con số nữa rất thực, rất lạc quan.

* Nhưng DN hiện vẫn gặp phải nhiều khó khăn trong việc đổi mới sáng tạo, đặc biệt là chính sách hỗ trợ, thưa bà?

- Ở VN, một điểm yếu căn cơ là chúng ta chưa có một thị trường công nghệ đúng nghĩa. Người có sáng kiến công nghệ thì không biết cung cấp cho ai, không được đánh giá, thẩm định đúng mức và ngược lại, DN có yêu cầu cũng chạy tìm "đỏ con mắt" cơ quan nghiên cứu phù hợp cho mình. Thậm chí muốn mua công nghệ, thiết bị không biết hỏi ai cho an tâm.

Có thể nói trong tam giác đổi mới sáng tạo với ba chủ thể là Nhà nước, DN và cơ quan nghiên cứu, hầu như chưa kết nối với nhau tốt. Chẳng hạn, một lãnh đạo Bộ Khoa học và công nghệ cho biết bộ này từng đề nghị Luật thuế thu nhập $\mathrm{DN}$ cho phép $\mathrm{DN}$ phải dành ra tối thiểu 10\% lợi nhuận trước thuể để chi cho đổi mới sáng tạo, nhưng luật ban hành chỉ cho phép dành tối đa $10 \%$ chứ không phải tối thiểu. Chỉ khác nhau giữa tối thiểu với tối đa mà sự khác biệt rất xa về chủ trương thúc đẩy hay không việc đổi mới sáng tạo trong DN. Việc xin trợ cấp cho hoạt động đổi mói sáng tạo thì chậm và nhiêu khê về thủ tục đển mức có DN được cấp xong phải năn nỉ "được khồng nhận trợ cấp".

* Sau cuộc khảo sát này, các tổ chức liên quan sẽ có những động thái gì để cải thiện những hạn chế như đã nêu?

- Chúng tôi đang có một dự án liên kết với các viện, trường để mời họ "chào hàng" các sáng kiển, công trình cho DN. Hiện nay, khởi đầu là với Đại học Bách khoa TP.HCM và sau đó, với các đại học có chuyên khoa về chế biến nông sản, sản xuất công nghệ phẩm. Đã xây dựng nền tảng ban đầu cho câu lạc bộ đổi mói sáng tạo. Đây sẽ là nơi kết nối, tương tác, cùng nhau chia sẻ thông tin, kinh nghiệm, cơ hội kinh doanh, cũng là nơi tổ 
chức các chương trình hội thảo, huấn luyện về đổi mới sáng tạo, hướng tới những bước chuẩn bị ban đầu cho thị trường công nghệ của VN...

* Ông Nguyễn Thể Hà (Công ty co khí nông nghiệp Bùi Văn Ngọ, Long An):

Trước đây, gần như một mình chúng tôi cứ tự mình làm mà không có ai đồng hành. Thông qua dự án đổi mới này, chúng tôi thật sự kỳ vọng sẽ nâng cao được năng lực cạnh tranh quốc gia cho nông nghiệp, tăng sức cạnh tranh cho nông sản Việt. Đồng thời, đổi mới sáng tạo không chỉ đổi mới máy móc mà cũng cần đổi mới tư duy của người nông dân, đổi mới phương thức sản xuất cho họ, tổ chức lại hình thức.

* Bà Lê Thị Thanh Lâm (phó tổng giám đốc Saigon Food):

Cuộc khảo sát cho chúng tôi cái nhìn toàn diện hơn về "sức khỏe" của doanh nghiệp, biết được mình còn thiếu và yếu thứ gì. Thông qua chương trình như thế này, chúng tôi cũng thật sự kỳ vọng sẽ nhận được nhiều sự hỗ trợ từ Nhà nước, từ các đơn vị nghiên cứu, các viện, trường đại học để doanh nghiệp thật sự có động lực hơn nữa trong đổi mới và sản xuất. 
